\title{
Ocular Reconstruction in a Newborn with MOTA Syndrome
}

\author{
Ran Stein ${ }^{1 *}$, Hana Leiba ${ }^{2}$, Arie Markovits ${ }^{2}$ and Asher Milstein ${ }^{2}$ \\ ${ }^{1}$ Ophthalmology Department, Hôpital Maisonneuve-Rosemont, Canada \\ ${ }^{2}$ Ophthalmology Department, Kaplan Medical Center, Israel
}

Submission: March 14, 2018; Published: April 04, 2018

*Corresponding author: Ran Stein, Ophthalmology Department, Hôpital Maisonneuve-Rosemont, 1634 Rue Saint-André. Montréal H2L 3T6, Québec, Canada, Tel: 1-514-716-5234; Email: steinran@gmail.com

\begin{abstract}
Manitoba Oculo-Tricho-Anal (MOTA) syndrome is a rare autosomal-recessive syndrome. Ophthalmic manifestations include hypertelorism, anophthalmos or microphthalmos, and various degrees of cryptophthalmos or eyelid colobomas. Most affected individuals belong to the aboriginal 0ji-Cree community of the Island Lake region in northern Manitoba, Canada. We will hereby describe the first case of a newborn with abortive cryptophthalmos due to MOTA syndrome in a Jewish offspring. Eyelid reconstruction was performed by reverse Hughes flap using the foreskin harvested during circumcision, and fornix reconstruction by conjunctival free graft. Functional and aesthetic long-term outcomes are good.
\end{abstract}

Keywords : Manitoba Oculotrichoanal (MOTA) Syndrome; Abortive cryptophthalmos

\section{Introduction}

Abortive cryptophthalmos is a rare congenital condition in which a colobomatous eyelid is fused with the cornea. When large enough, this may lead to sever exposure keratopathy, impaired vision and infections. The reconstruction challenge requires addressing both the eyelid deficit and the impaired fornix, and often necessitates prompt intervention and multiple surgeries. Abortive cryptophthalmos can be the manifestation of a congenital syndrome, such as Fraser Syndrome or, as in our case, Manitoba Oculotrichoanal (MOTA) Syndrome. This report describes the first case of a Jewish offspring with MOTA Syndrome, the unique reconstruction that was performed, and long-term follow-up and results.

\section{Report of a case}

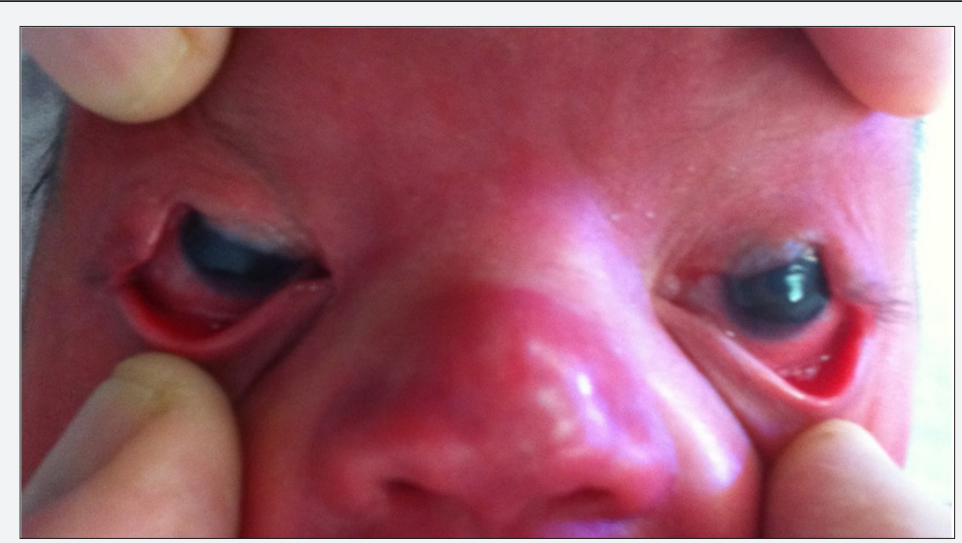

Figure 1: Abortive cryptophthalmos manifests as bilateral medial upper eyelid coloboma with fibrovascular adhesions between the colobomatous eyelids and the cornea.

Urgent ophthalmologist consultation was called for a baby who had just been born "without eyelids". On examination, bilateral abortive cryptophthalmos and hypertelorism were found. In both eyes, the colobomas involved more than half of the upper eyelids nasally, and a fibrovascular tissue fused the colobomatous eyelid to the cornea (Figure 1). In the right eye the 


\section{JOJ Ophthalmology}

fibrovascular adhesion was more extended than in the left, and obscured the visual axis. The rest of the ocular examination was normal. Non-ocular pathologies were bifid nose, and the lack of temporal scalp hairline with absence of defined eyebrows (Figure $2 \mathrm{a} \& 2 \mathrm{~b}$ ). The parents were both Jewish, Buchara-origin, second degree cousins with unremarkable medical history. Pregnancy was normal, and routine ultrasound scans were unexceptional. Three older siblings were all healthy, except for one sister with a similar nose shape as the newborn. Genetic testing confirmed the diagnosis of MOTA syndrome for both the newborn and his sister.

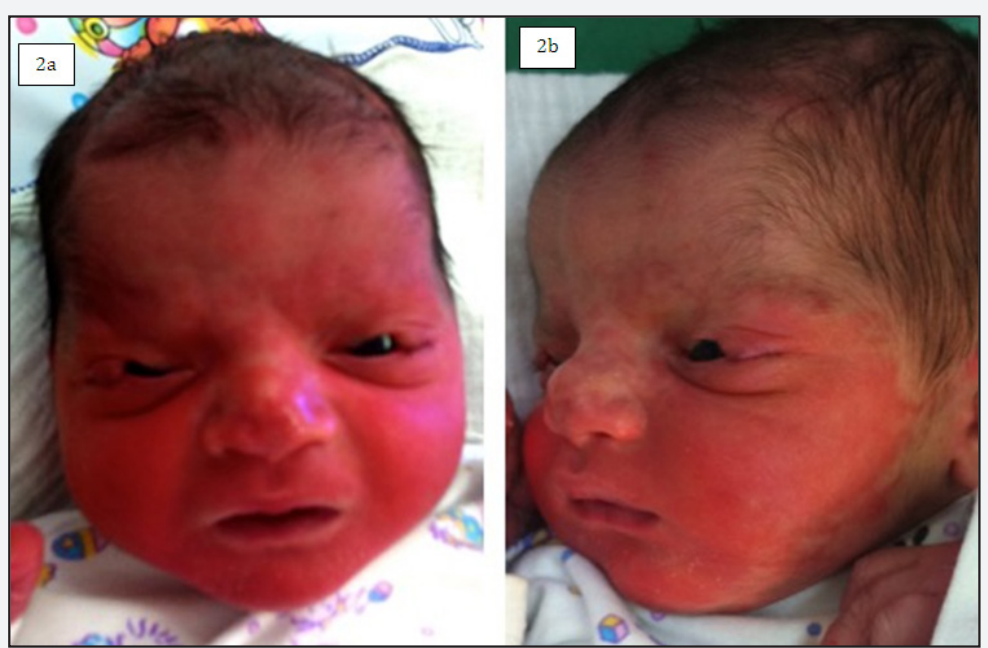

Figure 2a (right): : Abortive cryptophthalmos and hypertelorism, as well as bifid nose. Figure $2 \mathrm{~b}$ (left): Aberrant scalp hairline with the absence of defined eyebrows.

The severity of corneal exposure in both eyes called for urgent surgical intervention. Seven days post labor, the baby underwent circumcision and eyelid reconstruction. The adhesions were peeled off the cornea, and eyelid reconstruction was performed by reverse modified Hughes technique with a skin graft taken from the foreskin placed as anterior lamella. The eyes remained covered by the blood-supplying flap pedicle, allowing for vascularization of the posterior flap and anterior graft (Figure $3 a)$. The second stage of the procedure was carried out four weeks later. The eyelids were divided into upper and lower at the level of the reformed upper eyelid margin (Figure 3b). Tenzel semicircular rotation flaps were required in both eyes to allow tension-free closure of upper eyelid defects. Rehabilitation of the left eye was unremarkable. However, the right eye required rereconstruction of the fornix due to fusion between the bulbar and the palpebral conjunctiva. This was done using free conjunctival graft taken from the inferior bulbar conjunctiva. In the same eye, several consecutive procedures were required in order to peel membranes off the corneas and to release adhesions between the conjunctiva and the extraocular muscles.

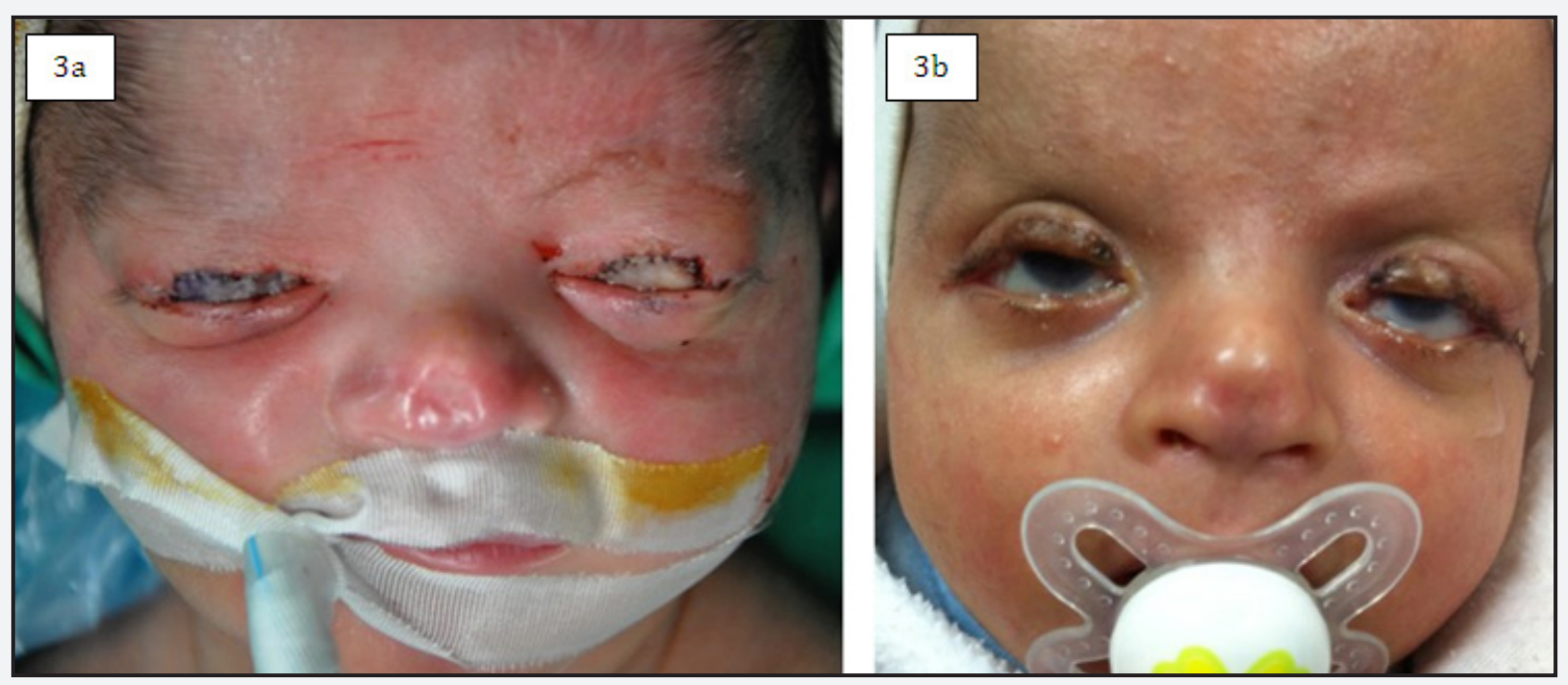

Figure 3a (left) : At the end of the first stage of Reverse Hughes procedure. The eyes are covered by pedicle flap from the lower eyelid and free graft made of the prepuce. Figure $3 \mathrm{~b}$ (right): A few weeks following the second stage of the procedure, good upper eyelid contour in both eyes. 


\section{Results}

During the years, the child was treated with lubricants and aggressive anti-amblyopic treatment. A strabismus operation was performed in right eye in light of severe esotropia due to adhesions. At his last examination, the child is six years old. The eyelids in both eyes maintain good position and contour. The cornea is irregular in the right eye, with vascularized opacifications nasally and centrally, and in the left it is mostly clear except for small superior panus. Visual acuity is hand motion on the right eye, and $6 / 15$ on the left. The refraction in the right eye is impossible to obtain, in the left it is $+5.00 /+2.50 \mathrm{X}$ 50 . The right eye is exotropic up to 25 prism diopters. The child maintains normal cognitive and social development.

\section{Discussion}

Manitoba Oculo-Tricho-Anal (MOTA) syndrome was introduced in 1992 as a familial syndrome that affected six siblings of an Indian Oji-Cree family from Manitoba, Canada [1]. Up to date, twenty-nine cases have been described in the medical literature, sixteen of them among the same Indian tribe, and the rest were European or Asian-origin [2-8]. This case was briefly described from a molecular-genetic perspective a few years ago [8]. MOTA syndrome is characterized by ocular manifestations such as hypertelorism, anophthalmos or microphthalmos, and various degrees of unilateral or bilateral cryptophthalmos or coloboma [1,2]. Scalp hair typically extends from the temple region to the ipsilateral affected eye with absence or interrupted eyebrow. Non-ocular abnormalities include bifid nose or wide nose with notched tip, abdominal wall defects such as omphalocele or umbilical hernia, and anal stenosis or anterior displacement [2]. Affected individuals seem to gain normal motor, social and verbal skills, although development may be influenced by visual impairment in cases of severe eye defects [2].

MOTA syndrome is autosomal recessive with variable penetrance, with clinical features present in $50 \%$ or more of cases diagnosed. The manifestations and degree of severity vary even among affected members of the same family [2].

The phenotype of MOTA syndrome overlaps with that of Fraser syndrome, but does not share the severe additional facial, renal, auricular and cognitive abnormalities that highlight the latter [9].

The genetic etiology for Fraser syndrome is varied, but is largely caused by mutations in FRAS1 (Fraser Syndrome 1 homolog, chromosome 4) and FREM2 (FRAS1 Related Extracellular Matrix protein, chromosome 13) genes [10]. Both proteins combine with a third protein, FREM1 (FRAS1 Related Extracellular Matrix protein 1, chromosome 9), to form a triplex that takes part in the creation and stabilization of the dermis' basement membrane in the second week of pregnancy [11]. Loss of function of FREM1 protein was found related to another syndrome, characterized by bifid nose, renal agenesis, and anorectal malformations [12] (BNAR syndrome).The molecular etiology for MOTA syndrome establishes the genetic relation between the three syndromes. MOTA syndrome is also caused by mutations in the gene encoding to FREM1 [6]. In that matter, the phenotypes of Fraser, BNAR and MOTA syndromes are situated on a common spectrum that relates to FRAS-FREM complex disease $[6,8]$.

Treatment of MOTA Syndrome is tailored to the exhibited deformities and ranges from observation to surgical correction. The main concern of congenital upper eyelid colobomas is exposure keratopathy, which may lead to refractive errors and amblyopia, and in severe cases to corneal and ocular infections. The timing and the technique used for the surgical correction of such cases depend on the severity of the defect. Mild cases can be treated conservatively and the surgical correction delayed until the age of 3-4 years, when there is more eyelid tissue available for reconstruction $[13,14]$. However, when more than one third of the upper eyelid is missing, prompt intervention is usually required [15]. Our patient suffered from abortive cryptophthalmos, also called congenital symblepharon, involving more than half of the upper eyelid. This is a combination of upper eyelid coloboma and corneopalpebral adhesion, while the lower eyelid remains intact [16]. In cases of large eyelid defects such as ours, tarsoconjunctival flap has been reported with good outcome $[17,18]$. However, eyelid-sharing, two-stage techniques are likely to be required [14,15]. Procedure such as Cutler-Beard, reverse modified Hughes flap, or lower eyelid switch flap obscure the vision for a few weeks, therefore should be considered at the amblyopic age only when their benefit outweighs potential irreversible damage to vision [15]. The use of the prepuce as anterior lamella in eyelid reconstruction has been described in cases of eyelid burns, cicatrical entropion and also in coloboma and cryptophthalmos [18]. The prepuce is a double-layered fold of skin and mucous membrane, and very similar to palpebral skin in thickness [17]. Circumcision, performed traditionally in the Jewish male babies at the age of seven days, provided in our case plenty of tissue available as anterior lamella substance.

Tendency to recurrence of symblepharon dictates special attention to reconstruction and maintenance of the fornices as part of symblepharon correction [19]. Various materials have been used to ensure functional fornices, among which are amniotic membrane [20,21], oral mucous membrane, hard palate or cartilage grafts, synthetic materials such as polytetrafluoroethylene and also autologous conjunctiva [22], as was done in our case. It should be noted that tendency for recurrence of the fibrovascular tissue may lead to adhesions of the extra-ocular muscles and cause strabismus [15], as occured in our case. Management and maintenance of viable conjunctiva and fornices are crucial, as well as strabismus surgery if required.

\section{Conclusions}

MOTA syndrome is extremely rare. Only a few affected individuals have been described outside the Oji-Cree tribe, and this is the first case among Jewish population. Severe upper 
eyelid defects comprise a serious challenge for the ophthalmic surgeon. In our case, repair of abortive cryptophthalmos was done using the prepuce harvested during circumcision, as part of reverse modified Hughes flap procedure. To our knowledge, this is the first case described in the literature that uses this combination of techniques, and also the first case to describe the long-term outcome of abortive cryptophthalmos reconstruction. It should be noted that the right eye, in which the abortive cryptophthalmos was more severe at presentation, exhibited a more complex clinical path: a conjunctival autograft was needed to maintain a viable fornix, and a few consecutive surgeries were required to release adhesions and correct strabismus. Reconstruction resulted in viability of ocular structures in both eyes and good cosmetic outcome.

\section{Conflict of Interest}

The authors have no financial or other conflicts of interest to disclose.

\section{Acknowledgements}

The case and the photos are published under permission and written consent of the patient's legal guardians.

\section{References}

1. Marles SL, Greenberg CR, Persaud TV, Shuckett EP, Chudley AE (1992) New familial syndrome of unilateral upper eyelid coloboma, aberrant anterior hairline pattern, and anal anomalies in Manitoba Indians. Am J Med Genet 42(6): 793-799.

2. Li C, Slavotinek A, Chudley AE (2008) Manitoba Oculotrichoanal Syndrome. GeneReviews ${ }^{\mathrm{T}}$. University of Washington, Seattle, Seattle (WA), USA.

3. Yeung A, Amor D, Savarirayan R (2009) Familial upper eyelid coloboma with ipsilateral anterior hairline abnormality: two new reports of MOTA syndrome. Am J Med Genet A 149A(4): 767-769.

4. Li C, Marles SL, Greenberg CR, Chodirker BN, van de Kamp J, et al. (2007) Manitoba Oculotrichoanal (MOTA) syndrome: report of eight new cases. Am J Med Genet A 143A(8): 853-857.

5. Mitter D, Schanze D, Sterker I, Müller D, Till H, et al. (2012) MOTA Syndrome: Molecular Genetic Confirmation of the Diagnosis in a Newborn with Previously Unreported Clinical Features. Mol Syndromol 3(3): 136-139.

6. Slavotinek AM, Baranzini SE, Schanze D, Labelle-Dumais C, Short KM, et al. (2011) Manitoba-oculo-tricho-anal (MOTA) syndrome is caused by mutations in FREM1. J Med Genet 48(6): 375-382.

7. Chacon-Camacho OF, Zenker M, Schanze D, Ledesma-Gil J, Zenteno JC (2017) Novel FREM1 mutations in a patient with MOTA syndrome: Clinical findings, mutation update and review of FREM1-related disorders literature. Eur J Med Genet 60(3): 190-194.
8. Nathanson J, Swarr DT, Singer A, Liu M, Chinn A, et al. (2013) Novel FREM1 mutations expand the phenotypic spectrum associated with Manitoba-oculo-tricho-anal (MOTA) syndrome and bifid nose renal agenesis anorectal malformations (BNAR) syndrome. Am J Med Genet A 161A(3): 473-478.

9. Mateo RK, Johnson R, Lehmann OJ (2012) Evidence for additional FREM1 heterogeneity in Manitoba oculotrichoanal syndrome. Mol Vis 18: 1301-1311.

10. Petrou P, Makrygiannis AK, Chalepakis G (2008) The Fras1/Frem family of extracellular matrix proteins: structure, function, and association with Fraser syndrome and the mouse bleb phenotype. Connect Tissue Res 49(3): 277-282.

11. Smyth I, Du X, Taylor MS, Justice MJ, Beutler B, Jackson IJ (2004) The extracellular matrix gene Frem1 is essential for the normal adhesion of the embryonic epidermis. Proc Natl AcadSci U S A 101(37): 1356013565.

12. Alazami AM, Shaheen R, Alzahrani F, Snape K, Saggar A, et al. FREM1 mutations cause bifid nose, renal agenesis, and anorectal malformations syndrome. Am J Hum Genet 85(3): 414-418.

13. Lodhi AA, Junejo SA, Khanzada MA, Sahaf IA, Siddique ZK (2010) Surgical outcome of 21 patients with congenital upper eyelid coloboma. Int J Ophthalmol 3(1): 69-72.

14. Seah LL, Choo CT, Fong KS. Congenital upper lid colobomas: management and visual outcome. Ophthal Plast Reconstr Surg 18(3): 190-195.

15. Grover AK, Chaudhuri Z, Malik S, Bageja S, Menon V. Congenital eyelid colobomas in 51 patients. J Pediatr Ophthalmol Strabismus 46(3): 151159.

16. Nouby G (2002) Congenital upper eyelid coloboma and cryptophthalmos. Ophthal Plast Reconstr Surg 18(5): 373-377.

17. Hoyama E, Limawararut V, Malhotra R, Muecke J, Selva D (2007) Tarsomarginal graft in upper eyelid coloboma repair. J AAPOS 11(5): 499-501.

18. Hashish A, Awara AM (2011) One-stage reconstruction technique for large congenital eyelid coloboma. Orbit 30(4): 177-179.

19. Ankola PA, Abdel-Azim H (2003) Congenital bilateral upper eyelid coloboma. J Perinatol 23(2): 166-167.

20. Stewart JM, David S, Seiff SR Amniotic membrane graft in the surgical management of cryptophthalmos. Ophthal Plast Reconstr Surg 18(5): 378-380.

21. Fung AT, Martin P, Petsoglou C, Kourt G (2009) Repair of isolated abortive cryptophthalmos with lower eyelid switch flap and amniotic membrane graft. Ophthal Plast Reconstr Surg 25(2): 158-161.

22. Walton WT, Enzenauer RW, Cornell FM (1990) Abortive cryptophthalmos: a case report and a review of cryptophthalmos. J Pediatr Ophthalmol Strabismus 27(3): 129-132. 
Your next submission with Juniper Publishers will reach you the below assets

- Quality Editorial service

- Swift Peer Review

- Reprints availability

- E-prints Service

- Manuscript Podcast for convenient understanding

- Global attainment for your research

- Manuscript accessibility in different formats

( Pdf, E-pub, Full Text, Audio)

- Unceasing customer service

Track the below URL for one-step submission https://juniperpublishers.com/online-submission.php 